\title{
Chitosan Nanoparticles Loaded with Carvacrol and Carvacryl Acetate for Improved Anthelmintic Activity
}

\author{
Weibson P. P. André, ${ }^{a}$ José R. Paiva Jr., ${ }^{b}$ Géssica S. Cavalcante, ${ }^{a, c}$ Wesley L. C. Ribeiro, ${ }^{a, d}$ \\ José V. de Araújo Filho, ${ }^{a}$ Bruno C. Cavalcanti, ${ }^{d}$ Selene M. de Morais, ${ }^{\circ}{ }^{c}$ Lorena M. B. de Oliveira, ${ }^{a}$ \\ Claudia M. L. Bevilaqua ${ }^{a}$ and Flávia O. M. S. Abreu ${ }^{\circledR * b}$
}

${ }^{a}$ Laboratório de Doenças Parasitárias, Programa de Pós-Graduação em Ciências Veterinárias, Universidade Estadual do Ceará, 60714-903 Fortaleza-CE, Brazil

${ }^{b}$ Laboratório de Química Analítica e Ambiental, Programa de Pós-Graduação em Ciências Naturais, Universidade Estadual do Ceará, 60714-903 Fortaleza-CE, Brazil

${ }^{c}$ Laboratório de Química de Produtos Naturais, Programa de Pós-Graduação em Ciências Veterinárias, Universidade Estadual do Ceará, 60714-903 Fortaleza-CE, Brazil

${ }^{d}$ Departamento de Fisiologia e Farmacologia, Faculdade de Medicina, Universidade Federal do Ceará, 60020-181 Fortaleza-CE, Brazil

\begin{abstract}
Carvacrol (CV) and carvacryl acetate (CVA) are bioactive compounds that have anthelmintic action and the nanoencapsulation may be an alternative to potentialize their efficacy. The aim of this work was to nanoencapsulate CV and CVA using chitosan/gums and evaluate cytotoxicity and the anthelmintic activity. A $2^{4}$ factorial experimental design was performed to determine the influence of gum type (arabic or chichá), amount of surfactant and the number of layers in the nanoencapsulation degree. CVA and CV presented encapsulation efficiency (EE) optimum values of 90 and 20\% (experiments 8 and 9), respectively. The monolayer and bilayer formulations presented maximum size of 479 and $811 \mathrm{~nm}$, respectively. Nanoencapsulated CVA (nCVA) with bilayer coating and higher surfactant levels showed good thermal stability and no toxicity. In vitro kinetics for nCVA with chitosan/chichá gum showed slower release profiles than nCVA with chitosan/gum arabic, with $50 \%$ release after 30 and $20 \mathrm{~h}$, respectively. CVA and nCVA at a concentration of $150 \mu \mathrm{g} \mathrm{mL}-1$ reduced the motility of $H$. contortus adult nematodes by 100 and $91.7 \%$, respectively. In summary, nCVA chitosan/chichá gum showed high encapsulation efficiency, favorable release rate and anthelmintic activity against $H$. contortus.
\end{abstract}

Keywords: polysaccharides, nanoparticle, drug delivery, anthelmintic activity, Haemonchus contortus

\section{Introduction}

Gastrointestinal nematodes, especially Haemonchus contortus, are globally recognized as a major challenge to the health, welfare and productivity in sheep and goats. ${ }^{1,2}$ The control of these nematodes is performed with the administration of anthelmintics, but the inappropriate use of these drugs has favored the selection of multiresistant populations in some parts of the world. ${ }^{3}$

New alternatives for the control of gastrointestinal nematodes are being studied, with a particular focus on

*e-mail: flavia.monteiro@uece.br the use of essential oils and their bioactive compounds. ${ }^{4-6}$ Carvacrol (2-methyl-5-(1-methylethyl) phenol) (CV) is a phenolic compound of the essential oils of plants of the Lamiaceae family and is mainly found in the genera Origanum and Thymus. ${ }^{7}$ The CV presents high toxicity, and acetylation is an alternative which can potentiate its biological activities and increase toxicological safety. ${ }^{6,8}$ Carvacryl acetate (CVA), acetylated derivative of carvacrol, showed anthelmintic activity on Schistosoma mansoni and gastrointestinal nematodes of small ruminant. ${ }^{5,9}$

The monoterpenes generally present low solubility in water, high volatility and short half-lives in the blood plasma. In this sense, nanoencapsulation has been proposed 
as an alternative to protect the physicochemical, promote a sustained release and increase the plasma bioavailability of bioactive compounds. ${ }^{10,11}$

The polyelectrolyte complexation is a technique which can be used for the nanoencapsulation of bioactive compounds. These complexes are mainly held together by hydrogen bonds, hydrophobic interactions and electrostatic association of the anionic and cationic biopolymers. ${ }^{12}$

Natural polymers have been proposed as substitutes for synthetic polymers due to their low toxicity, biodegradability and low cost. ${ }^{13,14}$ Chitosan, a cationic biopolymer formed from D-glucosamine and $N$-acetyl-D-glucosamine linked by $\beta$ (1-4) glycosidic bonds, is a deacetylated form of chitin, which is present in crustacean shells. ${ }^{15}$ The positively charged amino groups of chitosan interact with an anionic group of polysaccharides, such as the gum arabic (GA) and chichá gum (CG). GA is obtained from the trunk and branches of Acacia senegal or Acacia seyal trees. The chemical composition is generally $39-42 \%$ galactose, $24-27 \%$ arabinose, $12-16 \%$ rhamnose and $15-16 \%$ glucuronic acid. ${ }^{16}$ The CG is extracted from Sterculia striata, a plant of the Sterculiaceae family and native in Brazil. This CG is composed of uronic acid (42.2-49.2\%), rhamnose (23.8-28.8\%), galactose (19.3-23.4\%), xylose $(5.6-7.7 \%)$ and acetyl groups $(9.6 \%) .{ }^{17}$

The aim of this work was to study the influence of gum type (GA and CG), amount of surfactant (Tween 80) and number of coating layers (mono and bilayer) on the nanoencapsulation of CV and CVA. Nanoparticles (NPs), loaded with CV and CVA selected from their higher drug loading values were submitted for physicochemical characterization, and NPs loaded with CVA were also observed regarding kinetics of in vitro release, cytotoxicity and anthelmintic activity against $H$. contortus.

\section{Experimental}

\section{Materials}

CVA was obtained from the acetylation of CV (SigmaAldrich $^{\circledR}$, St. Louis, USA) according to the procedure of Matos. ${ }^{18}$ CVA was characterized by gas chromatographymass spectrometry (GC-MS) analysis and results are shown in the Supplementary Information (SI, Figure S1) section. The CG was collected from native trees in Quixadá, Ceará, Brazil, and it was purified as a sodium salt using the method described by Brito et al..$^{17}$ Acetic acid (Dinâmica ${ }^{\circledR}$, São Paulo, Brazil), GA (Dinâmica ${ }^{\circledR}$, São Paulo, Brazil), sodium tripolyphosphate (TPP) (Dinâmica ${ }^{\circledR}$, São Paulo, Brazil) and Tween 80 (Sigma-Aldrich ${ }^{\circledR}$, St. Louis, USA) were used as received. Chitosan (Polymar ${ }^{\circledR}$, Fortaleza, Ceará, Brazil) with a viscosity molar mass $(\mathrm{Mz}) 41.26 \times 10^{4} \mathrm{~g} \mathrm{~mol}^{-1}$ and $72 \%$ deacetylation degree was purified as described by Abreu et al. ${ }^{19}$

\section{Characterization of acid groups of the CG and GA}

The amount of acid groups of $\mathrm{CG}$ and GA were determined using back titration. $\mathrm{CG}$ and GA (50 mg) were weighed, $50 \mathrm{~mL}$ of distilled water was added, and the mixture was stirred for $1 \mathrm{~h}$. Subsequently, $15 \mathrm{~mL}$ of $0.09443 \mathrm{M} \mathrm{NaOH}$ and 3 drops of phenolphthalein indicator were added, and excess $\mathrm{NaOH}$ was titrated with $0.07512 \mathrm{M} \mathrm{HCl}$. The procedure was run in triplicate.

The monomeric unit used to determine the acidity content was glucuronic acid $\left(\mathrm{C}_{6} \mathrm{H}_{10} \mathrm{O}_{7}\right)$ with a molar mass of $194.139 \mathrm{~g} \mathrm{moL}^{-1}$.

\section{Production of nanoparticles (NPs)}

The NPs were produced from a polyelectrolytic complexation system according to Abreu et al. ${ }^{20}$ Chitosan was dissolved in $1 \%(\mathrm{v} / \mathrm{v})$ acetic acid aqueous solution at concentration $1 \%(\mathrm{~m} / \mathrm{v})$. Tween $80(33(\mathrm{~S} 1)$ or $100 \mu \mathrm{L}(\mathrm{S} 2))$ was added into $20 \mathrm{~mL}$ chitosan solution and subjected to mechanical stirring for $5 \mathrm{~min}$. Subsequently, $100 \mu \mathrm{L}$ of $\mathrm{CV}$ or CVA were added to the solution and placed in an ultrasonic bath (Ultra 800, Ciencor Scientific Ltda., São Paulo, Brazil) for $15 \mathrm{~min}$. Tween:CV or CVA ratio was 1:3 or $1: 1(\mathrm{v} / \mathrm{v})$. For the formation of the pre-nuclei of the NPs, a $0.1 \%(\mathrm{~m} / \mathrm{v})$ TPP drop was added (chitosan:TPP = 50:1) and the solution was subjected to magnetic stirring for $30 \mathrm{~min}$. Subsequently, $1 \%(\mathrm{~m} / \mathrm{v}) \mathrm{GA}$ or $\mathrm{CG}$ was added at a chitosan:gum ratio of $10: 1(\mathrm{~m} / \mathrm{m})$, and the solution was subjected to magnetic stirring for another $30 \mathrm{~min}$. Finally, the solution was centrifuged (Kasvi K14-4000, Curitiba, Brazil) at $4000 \mathrm{rpm}$ for $20 \mathrm{~min}$ in order to induce the nanoparticles sedimentation. The NPs recovered in monolayers (Mo) were lyophilized (L101, Liobras ${ }^{\circledR}$, São Paulo, Brazil). For the production of the bilayer (Bi) particles, the monolayer particles were suspended in $20 \mathrm{~mL}$ of distilled water and subjected to magnetic stirring. Dropwise, $1 \%(\mathrm{~m} / \mathrm{v})$ chitosan was added, and after $30 \mathrm{~min}$ the $1 \%(\mathrm{~m} / \mathrm{v})$ GA or CG solution was added, remaining under stirring for another $30 \mathrm{~min}$. Subsequently, the solution was centrifuged at $4000 \mathrm{rpm}$ for $20 \mathrm{~min}$; the supernatant was removed, and the bilayer NPs were subjected to the lyophilization process (L101, Liobras, São Carlos, Brazil).

\section{Encapsulation efficiency (EE)}

The EE of CV and CVA were determined by absorption 
spectroscopy with a UV-Vis PRO 800 (Shimadzu, Kyoto, Japan) at a wavelength of 271 and $276 \mathrm{~nm}$, respectively. A suspension of ethanol $96 \%$ containing $10 \mathrm{mg}$ NPs was kept under constant stirring for $48 \mathrm{~h}$. Subsequently, $2 \mathrm{~mL}$ of the solution was filtered using a $0.25 \mu \mathrm{m}$ syringe filter and their absorbances were determined. For comparison, calibration curves for $\mathrm{CV}$ and CVA were conducted by preparing for each compound a solution of $250 \mathrm{ppm}$ in ethanol (PA grade). Further dilutions were made to obtain concentrations of 200, $150,100,50,40,20$ and $30 \mathrm{ppm}$, resulting in the equations 1 and 2 for $\mathrm{CV}$ and CVA, respectively:

abs $=0.017$ conc $-0.004 ; R^{2}=0.998$

abs $=0.002$ conc $-0.020 ; R^{2}=0.999$

where: abs is the absorbance; conc is the oil concentration in $\mathrm{mg} \mathrm{L}^{-1} ; \mathrm{R}^{2}$ is the coefficient of determination.

\section{Experimental design and statistical analysis}

A $2^{4}$-replicate factorial design was performed to evaluate the factors that may influence the efficiency of encapsulation of CV and CVA. Based on the literature and previous studies, ${ }^{13,20,21}$ the independent variables chosen were the gum type, amount of surfactant, number of layers and type of active principle; the dependent was $\mathrm{EE}$ of $\mathrm{CV}$ and CVA. The factorial planning consisted of 16 experiments (Table 1) and the four factors were evaluated at two different levels, low $(-1)$ and high $(+1)$, as following: factor A: gum type: GA (-) and CG (+); factor B: surfactant:CVA or CV ratio: 1:3 (-) and 1:1 (+); factor C: number of layers: monolayer (-) and bilayer (+); factor D: active principle: CVA oil (-) and CV oil (+).

The factorial design was performed using Excel $^{\circledR}$ software $^{22}$ in statistical mode. Data were submitted to analysis of variance (ANOVA) and linear regression. Significant independent variables were selected with a level of significance $(p)$ of less than 0.05 and a reliability of $95 \%$.

\section{Characterization of nanoparticles}

The NPs were characterized by Fourier transform infrared spectroscopy (FTIR) using a Nicolet iS5 spectrophotometer (Thermo Scientific, Massachusetts, USA). The samples were prepared as potassium bromide pellets $(\mathrm{KBr})$ in the ratio of 1:20 (m/m) (sample: $\mathrm{KBr})$. Zeta potential and particle size was determined on a Nano ZetaSizer analyzer (Malvern 3600, Worcestershire, UK) using a laser wavelength of $632.8 \mathrm{~nm}$ and a fixed dispersion angle of $173^{\circ}$. Thermogravimetric analysis (TGA) was carried out in a Q600 SDT (TA Instruments, New Castle, USA), with ultra-pure nitrogen as the purge gas at a heating rate of $20{ }^{\circ} \mathrm{C} \mathrm{min}-1$ in aluminum pan.

Table 1. Experimental design of carvacrol and carvacryl acetate encapsulation conditions with encapsulation efficiency values

\begin{tabular}{|c|c|c|c|c|c|c|c|}
\hline \multirow{2}{*}{$\begin{array}{l}\text { Polymer } \\
\text { system }\end{array}$} & \multirow[b]{2}{*}{ Sample } & \multicolumn{4}{|c|}{ Independent variable } & \multicolumn{2}{|c|}{ Dependent variable } \\
\hline & & Factor A & Factor B & Factor $\mathrm{C}$ & Factor D & $\begin{array}{l}\text { Encapsulation } \\
\text { efficiency / \% }\end{array}$ & $\begin{array}{c}\text { Zeta potential / } \\
\mathrm{mV}\end{array}$ \\
\hline 1 & $\mathrm{GA} / \mathrm{S} 1 / \mathrm{Mo} / \mathrm{CVA}$ & -1 & -1 & -1 & -1 & 50.9 & \\
\hline 2 & $\mathrm{CG} / \mathrm{S} 1 / \mathrm{Mo} / \mathrm{CVA}$ & 1 & -1 & -1 & -1 & 41.0 & \\
\hline 3 & $\mathrm{GA} / \mathrm{S} 2 / \mathrm{Mo} / \mathrm{CVA}$ & -1 & 1 & -1 & -1 & 45.2 & \\
\hline 4 & $\mathrm{CG} / \mathrm{S} 2 / \mathrm{Mo} / \mathrm{CVA}$ & 1 & 1 & -1 & -1 & 58.2 & \\
\hline 5 & $\mathrm{GA} / \mathrm{S} 1 / \mathrm{Bi} / \mathrm{CVA}$ & -1 & -1 & 1 & -1 & 60.2 & \\
\hline 6 & CG/S1/Bi/CVA & 1 & -1 & 1 & -1 & 78.7 & \\
\hline 7 & $\mathrm{GA} / \mathrm{S} 2 / \mathrm{Bi} / \mathrm{CVA}$ & -1 & 1 & 1 & -1 & 77.1 & -2.19 \\
\hline 8 & $\mathrm{CG} / \mathrm{S} 2 / \mathrm{Bi} / \mathrm{CVA}$ & 1 & 1 & 1 & -1 & 90.2 & -1.27 \\
\hline 9 & $\mathrm{GA} / \mathrm{S} 1 / \mathrm{Mo} / \mathrm{CV}$ & -1 & -1 & -1 & 1 & 19.7 & -5.30 \\
\hline 10 & $\mathrm{CG} / \mathrm{S} 1 / \mathrm{Mo} / \mathrm{CV}$ & 1 & -1 & -1 & 1 & 18.3 & -1.38 \\
\hline 11 & $\mathrm{GA} / \mathrm{S} 2 / \mathrm{Mo} / \mathrm{CV}$ & -1 & 1 & -1 & 1 & 11.2 & \\
\hline 12 & $\mathrm{CG} / \mathrm{S} 2 / \mathrm{Mo} / \mathrm{CV}$ & 1 & 1 & -1 & 1 & 11.9 & \\
\hline 13 & $\mathrm{GA} / \mathrm{S} 1 / \mathrm{Bi} / \mathrm{CV}$ & -1 & -1 & 1 & 1 & 11.6 & \\
\hline 14 & $\mathrm{CG} / \mathrm{S} 1 / \mathrm{Bi} / \mathrm{CV}$ & 1 & -1 & 1 & 1 & 16.8 & \\
\hline 15 & $\mathrm{GA} / \mathrm{S} 2 / \mathrm{Bi} / \mathrm{CV}$ & -1 & 1 & 1 & 1 & 2.6 & \\
\hline 16 & $\mathrm{CG} / \mathrm{S} 2 / \mathrm{Bi} / \mathrm{CV}$ & 1 & 1 & 1 & 1 & 5.0 & \\
\hline
\end{tabular}

Factor A: type of gum; Factor B: surfactant content; Factor C: coating layers; Factor D: active principle; GA: gum arabic; S1: 33 LL Tween 80; Mo: monolayer; CVA: carvacryl acetate; CG: chichá gum; S2: $100 \mu \mathrm{L}$ Tween 80; Bi: bilayer; CV: carvacrol. 


\section{Release kinetics}

The release kinetics of NPs with higher EE content, obtained from experiments 7 (GA/S2/Bi/CVA) and 8 (CG/S2/Bi/CVA) were conducted using a dialysis system. For each sample, $60 \mathrm{mg}$ NPs were introduced into cellulose acetate membranes ( $14 \mathrm{kDa}$ pores) and dialyzed against $60 \mathrm{~mL}$ of phosphate buffer solution (PBS) and $1 \%(\mathrm{v} / \mathrm{v})$ Tween 80 at $\mathrm{pH} 7$ for $72 \mathrm{~h}$. Three aliquots of $2 \mathrm{~mL}$ were taken at every three hours and analyzed by spectrophotometry in the Genesys 10S UV-Vis (Thermo Fisher Scientific, New York, USA). Thus, the concentration of CVA present in the medium was calculated using a calibration curve in PBS at $\mathrm{pH} 7$ resulting in equation 3:

abs $=0.0028$ conc $-0.0368 ; R^{2}=0.994$

The mechanisms of release of CVA from the NPs were evaluated using the zero order, first order, Higuchi, HixsonCrowell, and Korsmeyer-Peppas mathematical models. ${ }^{23}$

Toxicity test

\section{Cytotoxicity}

The cytotoxicity test was performed using cell cultures of murine fibroblasts (L929 cell line) as a model, and the treatments, at concentrations ranging from 1.56 to $300 \mu \mathrm{g} \mathrm{mL} \mathrm{m}^{-1}$, were divided into the following groups: G1: CVA; G2: NPs experiments 7 (GA/S2/Bi/CVA); G3: NPs experiments 8 (CG/S2/Bi/CVA); G4: polymer matrix (chitosan/CG); G5: polymer matrix (chitosan/GA) and G6: dimethyl sulfoxide (DMSO, 0.1\%). The L929 cells were purchased from Rio de Janeiro Cell Bank (Rio de Janeiro, Brazil) and maintained in Dulbecco's modified Eagle medium (DMEM) supplemented with $10 \%$ fetal bovine serum, $2 \mathrm{mM}$ glutamine, $100 \mathrm{U} \mathrm{mL}^{-1}$ penicillin and $100 \mu \mathrm{g} \mathrm{mL} \mathrm{m}^{-1}$ streptomycin at $37{ }^{\circ} \mathrm{C}$ with $5 \% \mathrm{CO}_{2}$. Cells were plated in 96-well test plates at a density equal to $0.1 \times 10^{6}$ cells $\mathrm{mL}^{-1}$. The cell viability was determined by the reduction of the yellow dye 3-(4,5-dimethyl-2-thiazol)2,5-diphenyl-2H-tetrazolium bromide (MTT) to a purple formazan product as described by Mosmann. ${ }^{24}$ At the end of the incubation time ( $24 \mathrm{~h})$, the plates were centrifuged, and the medium was replaced by fresh medium $(200 \mu \mathrm{L})$ containing $0.5 \mathrm{mg} \mathrm{mL}^{-1}$ MTT. Three hours later, the MTT formazan product was dissolved in DMSO $(150 \mu \mathrm{L})$, and the absorbance was measured using a multiplate reader (Spectra Count, Packard, Ontario, Canada). The influence of the compound on cell toxicity was quantified as the percentage of control absorbance of the reduced dye at $550 \mathrm{~nm}$. Internucleosomal deoxyribonucleic acid (DNA) fragmentation, mitochondrial transmembrane potential $(\Delta \psi \mathrm{m})$ and DNA damage analysis (micronuclei $(\mathrm{MN})$ assay and alkaline comet assay) were also analyzed (SI section).

The tests were analyzed using averages and the corresponding confidence intervals based on the nonlinear regression generated using GraphPad Prism ${ }^{\circledR} 7.0$ software. ${ }^{25}$ Each sample was tested in triplicate in at least three independent experiments.

Ethics committee on animal welfare

This study was approved by the Ethics Committee of the Universidade Estadual do Ceará (protocol number: 6511846/2016).

\section{Adult worm motility}

Haemonchus contortus adults are obligate parasites and remain alive approximately $24 \mathrm{~h}$ after being withdrawn from the abomasum of sheep. In this way, to enable the evaluation of nanoencapsulated CVA, the NPs of experiment 8 (CG/S2/Bi/CVA) (presented higher EE) were incubated with PBS for $72 \mathrm{~h}$ (time determined according to the release curve), and subsequently incubated in the adult worm motility test (AWT).

The AWT assay was performed based on the methodology described by Hounzangbe-Adote et al. ${ }^{26}$ Adult worms were collected from an experimentally infected lamb four weeks after infection. Immediately after slaughtering, the abomasum were removed, opened and placed in $37^{\circ} \mathrm{C}$ saline solution. Mobile adult female worms were rapidly collected and put into 24-multiwell plates at a density of 3 worms per well in $1 \mathrm{~mL}$ of PBS at $37^{\circ} \mathrm{C}$ in the presence of $4 \%$ penicillin/streptomycin. After $1 \mathrm{~h}$ of incubation $\left(37{ }^{\circ} \mathrm{C}, 5 \%\right.$ carbon dioxide), $1 \mathrm{~mL}$ of 150,75 and $35.7 \mu \mathrm{g} \mathrm{mL}^{-1}$ of the following treatments were added to the worms: G1: CVA; G2: experiment 8 (CG/S2/Bi/CVA); $\mathrm{G} 3$ : polymer matrix (negative control) and G4: $100 \mu \mathrm{g} \mathrm{mL}^{-1}$ ivermectin (Ivomec ${ }^{\circledR}$, Merial Saúde Animal, São Paulo, Brazil). The measurements were performed on eight replicates per dose for each treatment. The motility of adult worms was noted by careful observation under inverted microscope at a magnification of $40 \times$ after 3, 6 and $12 \mathrm{~h}$.

Adult worm motility was evaluated as the number of motile worms/total number of worms per well. The motility results were expressed as the mean \pm standard error $(\mathrm{SE})$.

\section{Results and Discussion}

The titrations of glucuronic acid in $\mathrm{CG}$ and GA were 25.4 and $9.3 \%$, respectively. These results indicate that CG 
and GA are acidic polysaccharides, and this characteristic is fundamental for complexation with cationic polymers, such as chitosan. The CG presents a greater amount of negative charges, in relation to GA, and this is a common characteristic of the polysaccharides extracted from the plants of the genus Sterculia. ${ }^{17}$

\section{Nanoparticles encapsulation efficiency (EE)}

NPs produced with chitosan and gums were evaluated regarding EE, and the results are shown in Table 1. Polymeric systems for the nanoencapsulation of CVA presented EE ranging from 41 to $90 \%$. From all the NPs types produced, experiments 6 (CG/S1/Bi/CVA), 7 (GA/S2/Bi/CVA) and $8(\mathrm{CG} / \mathrm{S} 2 / \mathrm{Bi} / \mathrm{CVA})$ presented higher $\mathrm{EE}$, with values of 79,77 and $90 \%$, respectively. Experiment 8 was conducted in similar conditions to experiment 6 ; however, with higher surfactant content (S2), it was obtained an increase in the EE from 79 to $90 \%$. For the nanoencapsulation of carvacrol, better results were obtained in the experiments $9(\mathrm{GA} / \mathrm{S} 1 / \mathrm{Mo} / \mathrm{CV})$ and $10(\mathrm{CG} / \mathrm{S} 1 / \mathrm{Mo} / \mathrm{CV})$ with EE of 20 and 18\%, respectively. Regarding yield, the 16 runs presented results varying from 57.0 to $64.4 \%$.

The ANOVA analysis using $p<0.05$ indicated that the factors that influenced the most $\mathrm{EE}$ are the factors $\mathrm{C}$ (number of layers) and D (type of active principle), as well as the interactions of factors BD (amount of surfactant and type of active principle) and $\mathrm{CD}$ (number of layers and type of active principle). After linear regression, an equation which predicts the effect of the independent variables on EE was generated $\left(\mathrm{Y}_{1}\right.$, equation 4$)$ :

$\mathrm{Y}_{1}=37.4+5.37 \mathrm{C}-25.26 \mathrm{D}-4.71 \mathrm{DB}-8.51 \mathrm{CD}$,

$\mathrm{R}^{2}=0.964(p<0.05)$

The mean value of EE for CV and CVA is the intersection value $(37.4 \%)$ and the contributing factors were $C, D, D B$ and $C D$, explaining the $96.4 \%$ of the variability of EE. Substituting the variables C, D, DB and $\mathrm{CD}$ in equation 4 with normalized values $(-1,+1)$, an optimization of EE is theoretically achieved using $\mathrm{B}=+1$, $\mathrm{C}=+1, \mathrm{D}=-1$, giving a theoretic EE of $81.25 \%$. Under these conditions, NPs are developed with greater amount of surfactant $(\mathrm{B}=1)$, bilayer coating $(\mathrm{C}=1)$ and with the acetylated active principle $(D=-1)$. It is observed that the type of active principle is the main factor which influenced the EE. When CVA is encapsulated ( $\mathrm{D}=-1)$, there is an average increase of $25 \%$. In the interaction of the active principle with the surfactant ( $\mathrm{CD}$ factor), regarding the equation, when the surfactant was at the high level $(\mathrm{C}=+1)$, the term $\mathrm{CD}$ contributes $8.5 \%$ to $\mathrm{EE}$.
The hydrophilic-lipophilic balance (HLB) of a surfactant influences the micelle stabilization. Tween 80 , a non-ionic surfactant with HLB greater than 10, exhibits hydrophilic characteristics, where it rapidly moves to the aqueous phase after the organic phase is added. ${ }^{27}$ In this way, Tween 80 tends to interact more closely with compounds that are more liposoluble. CVA is more lipid soluble than $\mathrm{CV}$ due to the inclusion of the acetyl functional groups that increase the carbonyl chain of the compound. It is expected that a greater amount of surfactant is required to stabilize the hydrophobic moiety of the molecule and thus ensure its permanence within the polymer system. Conversely, CV is less lipophilic, and a lower amount of Tween 80 is needed to stabilize the molecule.

As for the number of layers, the bilayer system $(\mathrm{C}=+1)$ responds by a $5 \%$ increase in the value of EE of the NPs of CVA, as it promotes a greater protection of the activity in the polymer system. As stated in the literature, ${ }^{13} \mathrm{a}$ monolayer complex system may not provide full coverage of the surface through spaces or pores in the polymer network. The addition of an extra layer, as in the bilayer system, can ensure a more cohesive polymer coverage, reducing the voids of the complex structure, which may lead to a greater retention of the activity (higher EE) within the bilayer system and may also modify the kinetics release profile.

The four best nanoencapsulation systems of $\mathrm{CV}$ and CVA presenting higher EE were selected for further characterization. Those systems are experiments 7 (GA/ $\mathrm{S} 2 / \mathrm{Bi} / \mathrm{CVA}), 8$ (CG/S2/Bi/CVA), 9 (GA/S1/Mo/CV) and $10(\mathrm{CG} / \mathrm{S} 1 / \mathrm{Mo} / \mathrm{CV})$.

\section{Infrared spectroscopy (FTIR)}

The FTIR spectra of CV, CVA, chitosan, CG, GA and the above-mentioned systems are shown in SI section (Figures S1 and S2). The spectra of the NPs with GA, such as experiments $7(\mathrm{GA} / \mathrm{S} 2 / \mathrm{Bi} / \mathrm{CVA})$ and $9(\mathrm{GA} / \mathrm{S} 1 / \mathrm{Mo} / \mathrm{CV})$, presented bands at 1414,1416 and $1420 \mathrm{~cm}^{-1}$, regarding the stretching of the glucuronic acids of GA, overlapped with the asymmetrical amino bending vibrations at $1421 \mathrm{~cm}^{-1}$ of the chitosan. ${ }^{28}$ The spectra of the NPs with CG, such as experiment 8 (CG/S2/Bi/CVA) and $10(\mathrm{CG} / \mathrm{S} 1 / \mathrm{Mo} / \mathrm{CV})$, presented characteristic absorption peaks at 1728,1724 and $1733 \mathrm{~cm}^{-1}$, which corresponds to the stretching of the bond $\mathrm{C}=\mathrm{O}$ of the CG. ${ }^{17,29}$ The bands at 1092, 1089 and $1093 \mathrm{~cm}^{-1}$ are related to the chitosan $\mathrm{C}-\mathrm{O}-\mathrm{C}$ stretch. ${ }^{30}$ The band at $2960 \mathrm{~cm}^{-1}$ is attributed to the $\mathrm{sp}^{3} \mathrm{C}-\mathrm{H}$ stretching from the chitosan, GA and CG polysaccharide chains. A small peak around $3050 \mathrm{~cm}^{-1}$ in experiments 7,8 , and 9 is an indication of the presence of aromatic $\mathrm{C}-\mathrm{H}$ stretching 
from CVA. ${ }^{21}$ On the other hand, CVA was not detected, possibly due to overlapping with other bands of the biopolymer matrix.

\section{Zeta potential and particle size}

Zeta potential and particle sizes varied according to the number of layers and the type of active principle. The results of NPs zeta potential are shown in Table 1. The zeta potential of CVA or carvacrol NPs showed values ranging from -1.27 to $-5.30 \mathrm{mV}$. The negative zeta potential is related to the presence of carboxylic groups in the gum arabic and chichá gum..$^{29}$ The results of NPs size and distribution are shown in Figure 1. The NPs in monolayers, such as experiment 4 (CG/S2/Mo/CVA), $9(\mathrm{GA} / \mathrm{S} 1 / \mathrm{Mo} / \mathrm{CV})$ and $10(\mathrm{CG} / \mathrm{S} 1 / \mathrm{Mo} / \mathrm{CV})$, presented particle sizes of 479, 117 and $204 \mathrm{~nm}$, respectively, with unimodal distributions. The size of the NPs produced by experiment 4 were higher, possibly due to the greater amount of surfactant in the system, which increased the size of micelles.
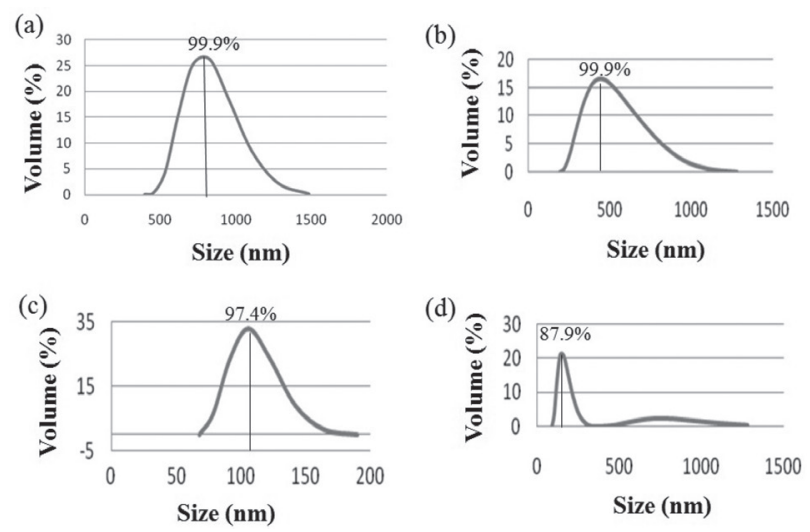

Figure 1. Particle size distribution of the of polymers: reaction number (a) 7 (GA/S2/Bi/CVA); (b) 8 (CG/S2/Bi/CVA); (c) $9(\mathrm{GA} / \mathrm{S} 1 / \mathrm{Mo} / \mathrm{CV})$ and (d) $10(\mathrm{CG} / \mathrm{S} 1 / \mathrm{Mo} / \mathrm{CV})$.
The NPs of experiment 7 (GA/S2/Bi/CVA) and 8 (CG/S2/Bi/CVA) presented particle size values of 810.6 and $459.4 \mathrm{~nm}$, respectively, higher than those of the systems in monolayers, due to the bilayer coating. The particle size of experiment 7 (GA/S2/Bi/CVA) is larger, possibly due to the lower number of carboxylic groups of GA present to interact by electrostatic forces with $\mathrm{R}-\mathrm{NH}_{3}{ }^{+}$ groups of chitosan during the formation of the monolayer, which remained positively charged at the surface of the particle. The addition of a new layer of chitosan/ GA possibly increased the $\mathrm{R}-\mathrm{NH}_{3}{ }^{+}$repulsion between the chains and, consequently, increased the size of the particles. ${ }^{29}$ In experiment $8(\mathrm{CG} / \mathrm{S} 2 / \mathrm{Bi} / \mathrm{CVA})$, the presence of a greater number of carboxylic groups in CG may have triggered a greater complexation with chitosan, reducing the particle size obtained in the system. In summary, experiments $7(\mathrm{GA} / \mathrm{S} 2 / \mathrm{Bi} / \mathrm{CVA})$ and $8(\mathrm{CG} / \mathrm{S} 2 / \mathrm{Bi} / \mathrm{CVA})$ were selected due to their optimized performance for further investigation regarding thermogravimetric analysis, in vitro release kinetics and cytotoxicity.

\section{Thermogravimetric analysis (TGA)}

Thermal stability was conducted in order to verify if the CVA was entrapped effectively into the NP system. CVA compound presented a single mass loss at $190^{\circ} \mathrm{C}$. NPs of experiments 7 (GA/S2/Bi/CVA) and $8(\mathrm{CG} / \mathrm{S} 2 / \mathrm{Bi} / \mathrm{CVA})$ presented two events of mass loss (Figure 2). The first stage for both systems occurred at approximately $65^{\circ} \mathrm{C}$, related to the loss of bound water and the second stage occurred respectively at 230 and $250{ }^{\circ} \mathrm{C}$. In summary, systems 7 and 8 showed thermal stability, where it was verified that CVA was successfully entrapped into chitosan/gums NPs system, where the second stage is related to the degradation of the biopolymers and CVA. In this case, CVA degradation was delayed to occur simultaneously with degradation of
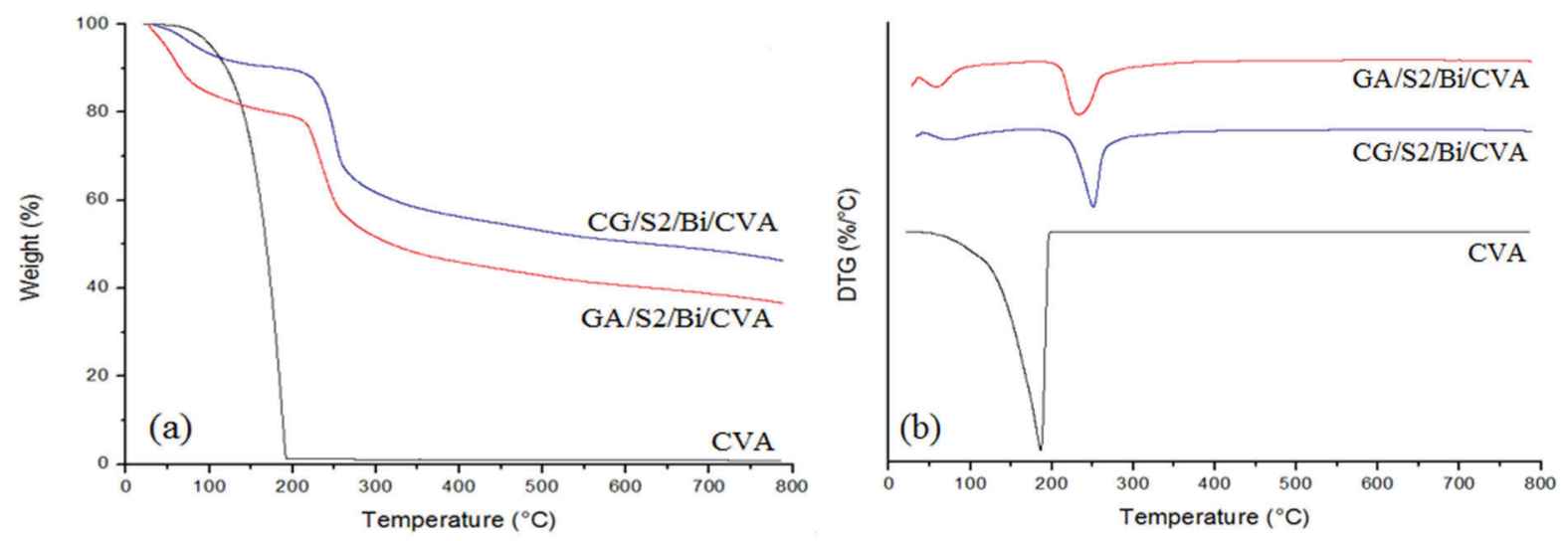

Figure 2. (a) Thermogravimetric analysis (TGA) and (b) dTG of CVA and nanoparticles of polymers reactions 7 (GA/S2/Bi/CVA) and 8 (CG/S2/Bi/CVA). 
the polysaccharide chains from the NPs, at approximately $260{ }^{\circ} \mathrm{C} .{ }^{28,31}$

\section{Release kinetics}

The release kinetics CVA of NPs from experiments 7 (GA/S2/Bi/CVA) and 8 (CG/S2/Bi/CVA) are presented in Figure 3. After $28 \mathrm{~h}$, it was observed that NPs of experiment 7, with the GA coating, showed faster release of CVA than those of reaction 8 , with the CG coating, with values of 74.1 and $50.4 \%$, respectively. Both systems reached equilibrium after $60 \mathrm{~h}$.

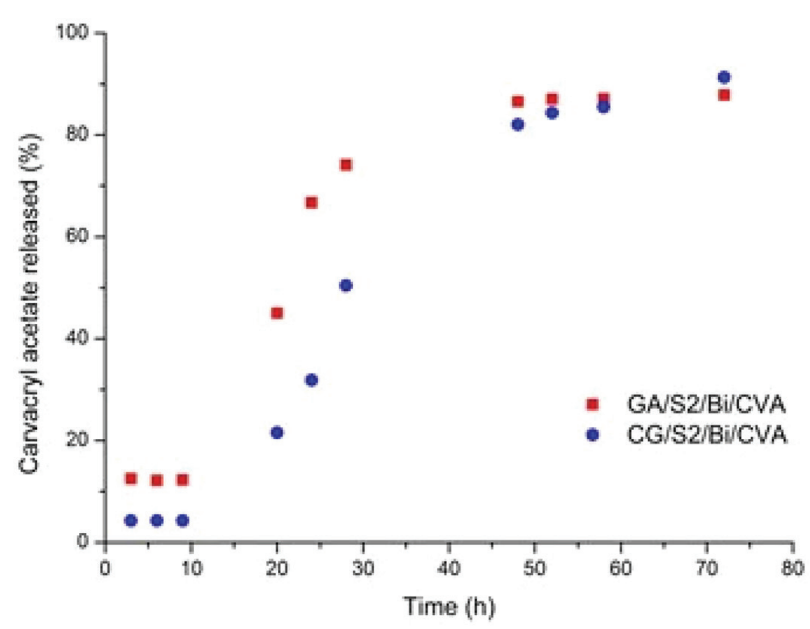

Figure 3. Release kinetics of the CVA-loaded nanoparticles of the systems 7 (GA/S2/Bi/CVA) and 8 (CG/S2/Bi/CVA).

The CVA release profiles from the NPs were analyzed by applying zero order, first order, Hixson-Crowell, Higuchi and Korsmeyer-Peppas kinetics. Linear regression was used to calculate the values of the release constants $(\mathrm{k})$ and the correlation coefficients ( $r$ ). The best correlation coefficients of NPs for experiments 7 and 8 were obtained by the Higuchi and Korsmeyer-Peppas models. A more detailed study on the Korsmeyer-Peppas model was performed, and its calculated kinetic parameters are shown in Table 2. Peppas ${ }^{32}$ proposed a kinetic theory using the value of the diffusion coefficient (n) in order to characterize the different mechanisms of release.

In the present study, the coefficient $\mathrm{n}$ assumed a value of 0.79 for experiment 7 (GA/S2/Bi/CVA), characterizing a
non-Fickian diffusion behavior. In this anomalous process, the phenomenon of relaxation of the polymer chains during the swelling process and diffusion are the main mechanisms responsible for the release of the CVA. ${ }^{33}$ In experiment 8 (CG/S2/Bi/CVA), the mechanism was transport case II, where the diffusion rate of the CVA is much greater than the relaxation of the chains of the material..$^{34}$ In this case, the release is mainly controlled by the diffusion process. The influence of polymer chain relaxation on the controlled release of CVA may be one of the reasons why the polymer bilayer increased the EE of the polymer systems used.

\section{Toxicity test}

CVA and NPs in experiments 7 (GA/S2/Bi/CVA) and $8(\mathrm{CG} / \mathrm{S} 2 / \mathrm{Bi} / \mathrm{CVA})$ presented no cytotoxicity (half maximal inhibitory concentration $\left.\left(\mathrm{IC}_{50}\right)>300 \mu \mathrm{g} \mathrm{mL} \mathrm{L}^{-1}\right)$ and genotoxicity/mutagenicity (Figure S3, SI section). The low toxicity of acetylated monoterpenes was also checked in the study ${ }^{8}$ evaluating thymol acetate cytotoxicity in murine macrophages-RAW 264.7. The NPs had no toxicity because the CVA and the biopolymers are non-toxic.

\section{Adult worm motility}

The results of the adult worm motility test are presented in Figure 4. CVA motility test is in Figure 4a and nCVA motility test is in Figure 4b. Results showed that live worms decreasing depended on the time and the concentration, where lower live worms' values indicate that motility was considerably reduced. Particularly, CVA and nCVA with a concentration of $150 \mu \mathrm{g} \mathrm{mL}^{-1}$ reduced the live worms population to values to 0 and $8.3 \%$, respectively, indicating that the inhibition on the worm motility were respectively 100 and $91.7 \%$. The motility of worm's was 0 and $87.5 \%$ in the positive and negative controls, respectively. The results of the adult worm motility test were dose-dependent.

The inhibition of $66.6 \%$ of the motility of adult nematodes exposed to $150 \mu \mathrm{g} \mathrm{mL}^{-1}$ of the CVA NPs at $6 \mathrm{~h}$ can be associated with the lower concentration of CVA in the medium, because the particles were still releasing the CVA, due to the neutral $\mathrm{pH}$ at which the test was

Table 2. Release kinetic parameters of carvacryl acetate from nanoparticles of polymer systems 7 (GA/S2/Bi/CVA) and 8 (CG/S2/Bi/CVA)

\begin{tabular}{|c|c|c|c|c|c|c|c|}
\hline \multirow[b]{2}{*}{ Sample } & \multicolumn{5}{|c|}{ Correlation coefficient (r) } & \multirow[b]{2}{*}{$\mathrm{k}$} & \multirow[b]{2}{*}{$\mathrm{n}$} \\
\hline & Zero order & First order & Hixson-Crowell & Higuchi & $\begin{array}{c}\text { Korsmeyer- } \\
\text { Peppas }\end{array}$ & & \\
\hline 7 (GA/S2/Bi/CVA) & 0.817 & 0.715 & 0.751 & 0.904 & 0.888 & 0.043 & 0.79 \\
\hline 8 (CG/S2/Bi/CVA) & 0.947 & 0.824 & 0.886 & 0.947 & 0.925 & 0.007 & 1.20 \\
\hline
\end{tabular}

k: Korsmeyer-Peppas release constant; n: diffusion coefficient; GA: gum arabic; S2: $100 \mu$ L Tween 80; Bi: bilayer; CVA: carvacryl acetate; CG: chichá gum. 

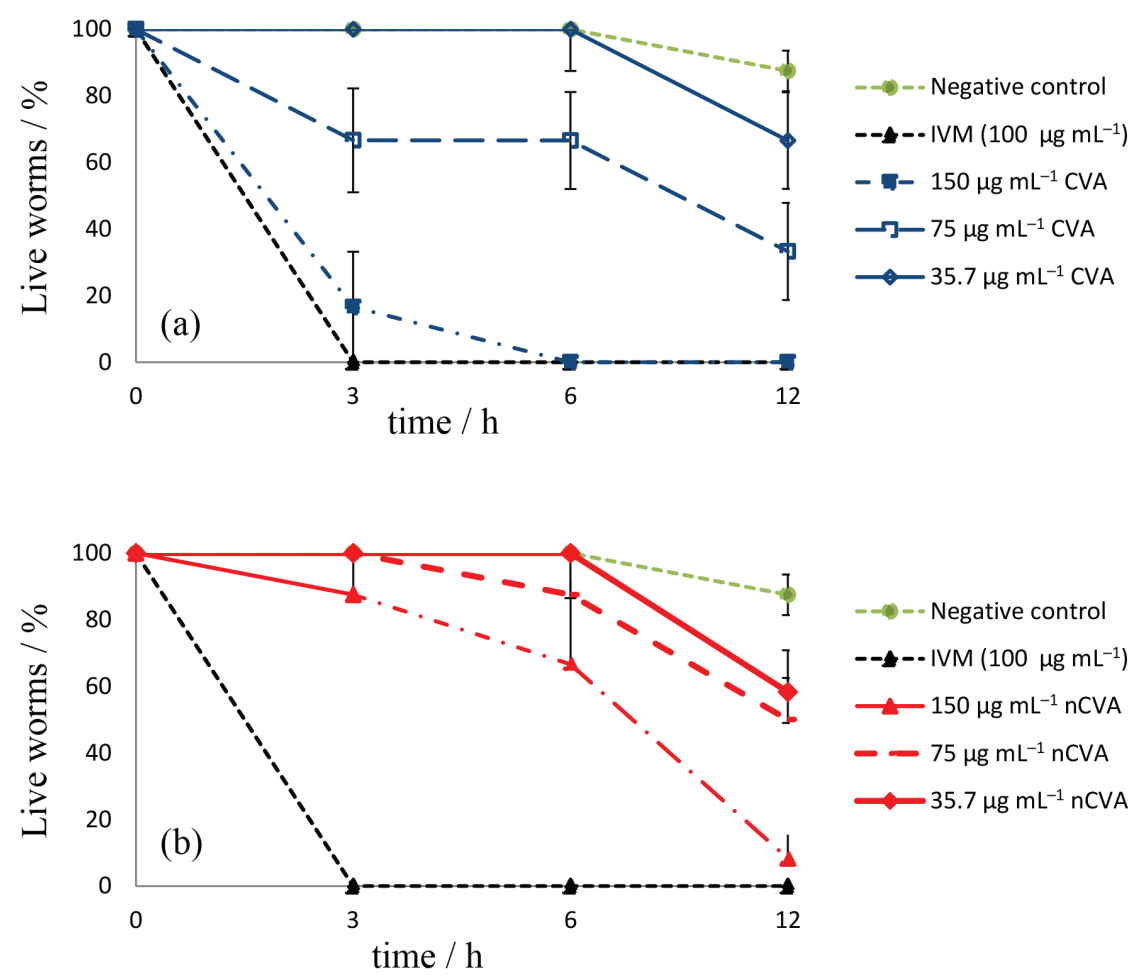

Figure 4. Effect of (a) carvacryl acetate (CVA), (b) nanoencapsulated carvacryl acetate (nCVA), and controls positive (ivermectin) and negative (polymer matrix) on inhibition of motility of adult Haemonchus contortus.

performed. In a study evaluating the anthelmintic activity of the albendazole-containing hydrogel on adult nematodes of Caenorhabditis elegans, the nematode mortality was evaluated over 10 days; after the third day of exposure, a greater activity of albendazole hydrogel was observed in relation to free albendazole. ${ }^{35}$ Sustained release of the bioactive compounds by the NPs may possibly increase the bioavailability and the time of exposure of the nematodes to these compounds, consequently potentiating the anthelmintic activity.

\section{Conclusions}

$\mathrm{CV}$ and CVA were nanoencapsulated with chitosan/ gums, where the NPs presented sizes ranging from 100 to $800 \mathrm{~nm}$ according to the reaction conditions. $\mathrm{CV}$ compound were more favorable using low surfactant levels with a monolayer system. However, CVA showed better encapsulation efficiency, using higher surfactant content with a bilayer polysaccharide chitosan-gum system. NPs of experiments 7 (GA/S2/Bi/CVA) and 8 (CG/S2/Bi/CVA) presented the best set of properties, showing no cytotoxicity and slow in vitro release rate. Experiment 8 showed an even slower release profile than experiment 7, with $50 \%$ release after $30 \mathrm{~h}$, and caused a $97 \%$ reduction of the motility of adult nematodes of $H$. contortus being highly effective. Thus, we conclude that nanoencapsulated CVA is a promising anthelmintic for the control of gastrointestinal nematodes of sheep and goats.

\section{Supplementary Information}

Supplementary data (methodology and results of the internucleosomal DNA fragmentation, mitochondrial transmembrane potential $(\Delta \psi \mathrm{m})$ and DNA damage analysis; FTIR spectra of CV, CVA, chitosan, CG and GA) are available free of charge at http://jbcs.sbq.org.br as PDF file.

\section{Acknowledgments}

Coordenação de Pessoal de Nível Superior (CAPES) and Conselho Nacional de Desenvolvimento Científico e Tecnológico (CNPq) provided financial support. Dr Bevilaqua has a researcher fellowship from $\mathrm{CNPq}$ (310663/2016-4-5).

\section{Author Contributions}

Weibson P. P. André was responsible for the conceptualization, data curation, formal analysis, investigation, methodology, project administration and writing review and editing; José R. Paiva Jr. for the formal analysis, methodology, software and visualization; Géssica 
S. Cavalcante for the formal analysis, investigation, methodology and visualization; Wesley L. C. Ribeiro for the formal analysis, investigation, methodology and software; José V. de Araújo Filho for the formal analysis, methodology, software and visualization; Bruno C. Cavalcanti for the formal analysis, investigation and methodology; Selene M. de Morais for the formal analysis, methodology and supervision; Lorena M. B. de Oliveira for the formal analysis, investigation, methodology and supervision; Flávia O. M. S. Abreu for the investigation, methodology, project administration, validation and writing original draft; Claudia M. L. Bevilaqua for the conceptualization, data curation, investigation, project administration, visualization and writing original draft.

\section{References}

1. Besier, R. B.; Kahn, L. P.; Sargison, N. D.; Van Wyk, J. A.; Adv. Parasitol. 2016, 93, 95.

2. Elmahalawy, S. T.; Halvarsson, P.; Skarin, M.; Höglund, J.; Vet. Parasitol. 2018, 261, 1 .

3. Kotze, A. C.; Prichard, R. K.; Adv. Parasitol. 2016, 93, 397.

4. Ribeiro, W. L. C.; Camurça-Vasconcelos, A. L. F.; Santos, J. M. L.; Macedo, I. T. F.; Ribeiro, J. C.; Oliveira, E. F.; Paula, H. C. B.; Bevilaqua, C. M. L.; Pesq. Vet. Bras. 2017, 37, 221.

5. André, W. P. P.; Ribeiro, W. L. C.; Cavalcante, G. S.; Santos, J. M. L.; Macedo, I. T. F.; Paula, H. C. B.; Freitas, R. M.; Morais, S. M.; Melo, J. V.; Bevilaqua, C. M. L.; Vet. Parasitol. 2016, 218,52 .

6. André, W. P. P.; Cavalcante, G. S.; Ribeiro, W. L. C.; Santos, J. M. L.; Macedo, I. T. F.; Paula, H. C. B.; Morais, S. M.; Melo, J. V.; Bevilaqua, C. M. L.; Rev. Bras. Parasitol. Vet. 2017, 26, 323.

7. Baser, K. H. C.; Curr. Pharm. Des. 2008, 14, 3106.

8. Morais, S. M.; Vila-Nova, N. S.; Bevilaqua, C. M. L.; Rondon, F. C. M.; Lobo, C. H.; Moura, A. A. A. N.; Sales, A. D.; Rodrigues, A. P. R.; Figueiredo, J. R.; Campello, C. C.; Wilson, M. E.; Junior, H. F. A.; Bioorg. Med. Chem. 2014, 22, 6250.

9. Moraes, J.; Carvalho, A. A. L.; Nakaro, E.; Almeida, A. A. C.; Marques, T. H. C.; Andrade, L. N.; Freitas, M. R.; Sousa, D. P.; Parasitol. Res. 2013, 112, 603.

10. Quintans, J. S. S.; Menezes, P. P.; Santos, M. R. V.; Bonjardim, L. R.; Almeida, J. R. G. S.; Gelain, D. P.; Araújo, A. A. S.; Quintans-Júnior, L. J.; Phytomedicine 2013, 20, 436.

11. Pitombeira, N. A. O.; Neto, J. G. V.; Silva, D. A.; Feitosa, J. P. A.; Paula, H. C. B.; Paula, R. C. M.; Carbohydr. Polym. 2015, 117,610 .
12. Minkal, M. A.; Bhatt, D. C.; Int. J. Biol. Macromol. 2018, 106, 1184.

13. Paula, H. C. B.; Sombra, F. M.; Cavalcante, R. F.; Abreu, F. O. M. S.; Paula, R. C. M.; Mater. Sci. Eng., C 2011, 31, 173.

14. Salamanca, C. H.; Yarce, C. J.; Moreno, R. A.; Prieto, V.; Recalde, J.; Carbohydr. Polym. 2018, 189, 31.

15. Abreu, F. O. M. S.; Oliveira, E. F.; Paula, H. C. B.; Paula, R. C. M.; Carbohydr. Polym. 2012, 89, 1277.

16. Sanchez, C.; Nigen, M.; Tamayo, V. M.; Doco, T.; Williams, P.; Amine, C.; Renard, D.; Food Hydrocolloids 2018, 78, 140.

17. Brito, A. C. F.; Silva, D. A.; Paula, R. C. M.; Feitosa, J. P. A.; Polym. Int. 2004, 53, 1025.

18. Matos, F. J. A.; Introdução à Fitoquímica Experimental, $2^{\text {nd }}$ ed.; Edições UFC: Fortaleza, 1997.

19. Abreu, F. O. M. S.; Castro, A. M.; Cavalcante, L. G.; Doudement, P. V.; Matos, J. E. X.; Nascimento, A. P.; Polímeros 2013, 23, 630 .

20. Abreu, F. O. M. S.; Bianchini, C.; Forte, M. M. C.; Kist, T. B. L.; Carbohydr. Polym. 2008, 74, 283.

21. Keawchaoon, L.; Yoksan, R.; Colloids Surf., B 2011, 84, 163.

22. Excel $^{\circledR}$, version 2010; Microsoft Corporation, USA, 2010.

23. Costa, P. J. C.; Rev. Bras. Cienc. Farm. 2002, 38, 141.

24. Mosmann, T.; J. Immunol. Methods 1983, 65, 55.

25. GraphPad Prism ${ }^{\circledR}$, version 7.0; GraphPad Software, San Diego, CA, USA, 2016.

26. Hounzangbe-Adote, M. S.; Paolini, V.; Fouraste, I.; Moutairou, K.; Hoste, H.; Res. Vet. Sci. 2005, 78, 155.

27. Guttoff, M.; Saberi, A. H.; McClements, D. J.; Food Chem. 2015, 171, 117.

28. Daoub, R. M. A.; Elmubarak, A. H.; Misran, M.; Hassan, E. A.; Osman, M. E.; J. Saudi Soc. Agric. Sci. 2018, 17, 241.

29. Paula, H. C. B.; Oliveira, E. F.; Carneiro, M. J. M.; de Paula, R. C. M.; Planta Med. 2017, 83, 392.

30. Yoksan, R.; Jirawutthiwongchai, J.; Arpo, K.; Colloids Surf., $B$ 2010, 76, 292.

31. Soares, P. I. P.; Machado, D.; Laia, C.; Pereira, L. C. J.; Coutinho, J. T.; Ferreira, I. M. M.; Novo, C. M. M.; Borges, J. P.; Carbohydr. Polym. 2016, 149, 382.

32. Peppas, N. A.; Pharm. Acta Helv. 1985, 60, 110.

33. Korsmeyer, R. W.; Gurny, R.; Doelker, E. M.; Buri, P.; Peppas, N. A.; Int. J. Pharm. 1983, 15, 25.

34. Sujja-Areevath, J.; Munday, D. L.; Cox, P. J.; Khan, K. A.; Int. J. Pharm. 1996, 139, 53.

35. Feng, Y.; Wang, F.; Zhang, X. W.; Bhutani, H.; Ye, B.; Parasitol. Res. 2017, 116, 921.

Submitted: October 1, 2019 Published online: March 17, 2020 